\title{
Avalanche ruggedness of parallel SiC Power MOSFETs
}

\author{
A. Fayyaz ${ }^{\mathrm{a}, *}$, B. Asllani ${ }^{\mathrm{a}}$, A. Castellazzi ${ }^{\mathrm{a}}$, M. Riccio ${ }^{\mathrm{b}}$, A. Irace $^{\mathrm{b}}$ \\ ${ }^{a}$ Power Electronics, Machines and Control Group, University of Nottingham, Nottingham NG7 2RD, UK \\ ${ }^{\mathrm{b}}$ Dept. of Electrical Engineering and Information Technologies, University of Naples Federico II, Naples, Italy
}

\begin{abstract}
The aim of this paper is to investigate the impact of electro-thermal device parameter spread on the avalanche ruggedness of parallel silicon carbide ( $\mathrm{SiC}$ ) power MOSFETs representative of multi-chip layout within an integrated power module. The tests were conducted on second generation $1200 \mathrm{~V}, 36 \mathrm{~A}-80 \mathrm{~m} \Omega$ rated devices. Different temperature-dependent electrical parameters were identified and measured for a number of devices. The influence of spread in measured parameters was investigated experimentally during avalanche breakdown transient switching events and important findings have been highlighted.
\end{abstract}

\section{Introduction}

Power modules usually comprise of many chips connected in series and parallel in order to obtain higher voltage and current ratings for higher power applications. However, as a result of paralleling multichips within an integrated power module, derating rules usually need to be imposed to account for the impact of electro-thermal parameter spread within devices alongside other mismatches that may arise due to packaging related issues. Electro-thermal device parameters such as on-state resistance $\left(\mathrm{R}_{\mathrm{DS}, \mathrm{ON}}\right)$, threshold voltage $\left(\mathrm{V}_{\text {th }}\right)$, breakdown voltage $\left(\mathrm{V}_{\mathrm{BD}}\right)$, trans-conductance $\left(\mathrm{g}_{\mathrm{f}}\right)$ and thermal impedance $\left(\mathrm{Z}_{\mathrm{th}}\right)$ as well as assembly layout related issues may result in significant thermal unbalances due to uneven current and power distribution within the power module during fast switching transient events (e.g. short-circuit and unclamped inductive switching). As a result of these mismatches, some devices would observe enhanced stress conditions as compared to others causing them to degrade faster and in some conditions, may also lead to premature destructive failure of the whole module $[1$, 2].

$\mathrm{SiC}$ is a wide bandgap semiconductor which possess high breakdown voltage, fast switching speed and excellent thermal conductivity which has subsequently resulted in rapid development of $\mathrm{SiC}$ Power MOSFET device technology over the past few years. As technology at discrete device level has

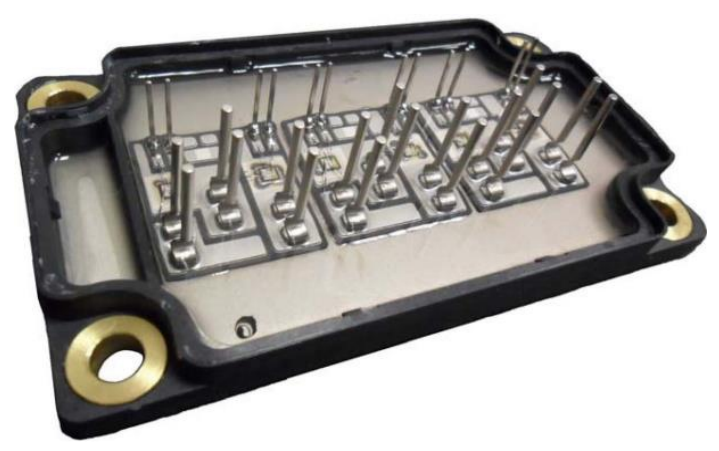

Fig. 1. Multi-chip layout of SiC MOSFET power module substantially improved, extensive industrial and research efforts are being made to produce power modules for applications such as photovoltaic, electric vehicles and automotive industry. However, device parameter mismatch within devices going in the module should be contained to avoid unacceptable temperature gradients inside the module during transient conditions. Fig. 1 represents a bespoke $\mathrm{SiC}$ power MOSFET module which can be used as either a 3-phase single chip half-bridge type of switch, or as a single-phase half-bridge with parallel chips for higher current rating [3].

Furthermore, in addition to the abovementioned reasons, mismatches and thermal unbalances within modules can also arise from the different cooling 
techniques implemented by the end-user which is not down to the manufacturer. Such mismatches and device parameter spread usually introduce temperature gradients $\left(10-15^{\circ} \mathrm{C}\right)$ in the module during nominal conditions. Such levels of temperature gradient may be acceptable during nominal operating conditions, however, this temperature gradient alongside device parameter spread can be found to be really critical for device's robustness during fast transient switching conditions and therefore motivates the basis of this dedicated study on SiC MOSFETs. Various recent studies presented in [4-7] have investigated the effect of parameter spread during on-state and double-pulse switching performance but no studies seem to exist demonstrating current sharing during avalanche breakdown operation. Some recent studies on single discrete devices during SC and UIS detailing electrothermal characterisation could also be found in [8 - 10].

\section{Device parameter spread and experimental results during avalanche breakdown}

\subsection{Methodology and Device Parameter Spread}

The study presented here focuses on unclamped inductive switching (UIS) of $1200 \mathrm{~V}, 36 \mathrm{~A}-80 \mathrm{~m} \Omega$ $\mathrm{SiC}$ power MOSFETs during paralleling operation. Circuit schematic used for paralleling devices is a modified double pulse test circuit to accommodate two devices in parallel as presented in Fig. 2. For this study, a total of 14 devices of same type were selected. The distribution of $\mathrm{V}_{\text {th }}$ values (case temperature; $\mathrm{T}_{\mathrm{CASE}}=$ $25^{\circ} \mathrm{C}$ ) for these 14 devices have been presented in Fig. 3. For example, in the worst case scenario, $\Delta \mathrm{V}_{\mathrm{th}}$ for two devices could easily be approximately up to $1 \mathrm{~V}$. Even-though, the measured values are within the specified data-sheet range, such huge $\Delta \mathrm{V}_{\text {th }}$ can be problematic when it comes to paralleling devices. Fig. 4 presents $V_{\text {th }}$ variation versus temperature for two devices which shows that the parameter spread is not strictly constant over range of $\mathrm{T}_{\mathrm{CASE}}$. It is worth noting that $\Delta \mathrm{V}_{\text {th }}$ at $25^{\circ} \mathrm{C}$ was $0.26 \mathrm{~V}$ which became $0.45 \mathrm{~V}$ at $150^{\circ} \mathrm{C}$.

Spread of $\mathrm{V}_{\mathrm{BD}}$ was also measured for $\mathrm{T}_{\mathrm{CASE}}=$ $25^{\circ} \mathrm{C}$ which is presented in Fig. 5. Here, in the worst case scenario, $\Delta \mathrm{V}_{\mathrm{BD}}$ of two devices could easily be up to $50 \mathrm{~V}$. Through examining the measured spread of the different parameters, experiments were designed to cover three different scenarios as presented in Table 1. As per the general trend observed here, the devices with lower $\mathrm{V}_{\text {th }}$ have higher $\mathrm{V}_{\mathrm{BD}}$ and vice versa.
However, this is not always the case as different scenarios that can occur are presented in Table 1.

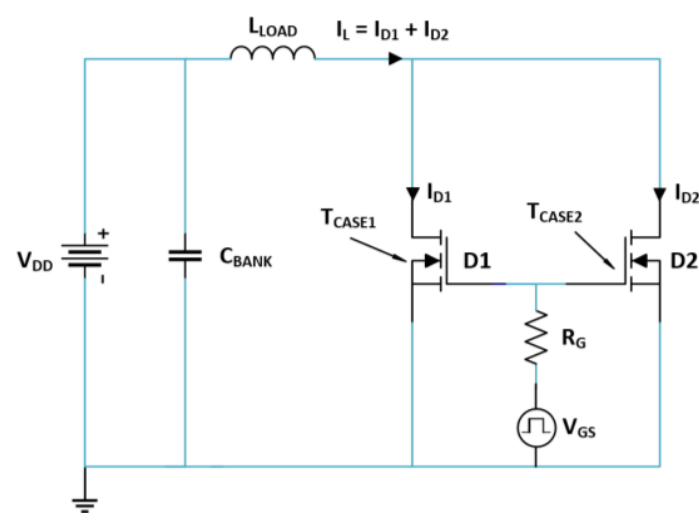

Fig. 2. UIS Circuit schematic for 2 parallel devices

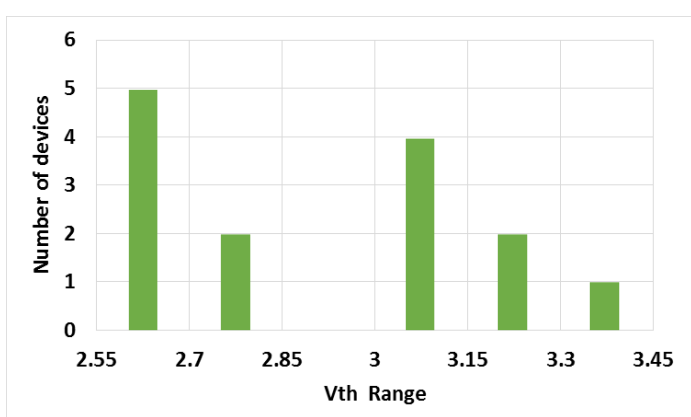

Fig. 3. Distribution of measured $\mathrm{V}_{\text {th }}$ for 14 device samples; $\mathrm{T}_{\mathrm{CASE}}=25^{\circ} \mathrm{C} ; \Delta \mathrm{V}_{\mathrm{th}}=0.92 \mathrm{~V}$ for worst case scenario

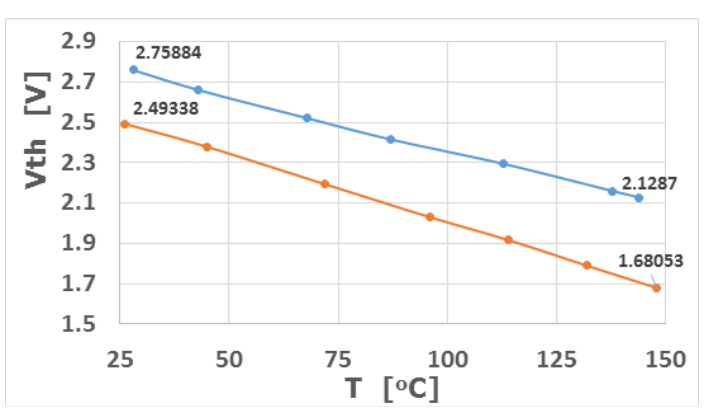

Fig. 4. $\mathrm{V}_{\text {th }}$ versus $\mathrm{T}_{\text {CaSe }}$ for 2 devices showing $\mathrm{V}_{\mathrm{th}}$ temperature variation

Table 1

Summary of different test scenarios

\begin{tabular}{|l|l|l|}
\hline Scenario & D1 & D2 \\
\hline $\mathrm{S} 1$ & Higher $\mathrm{V}_{\mathrm{BD}} ;$ Lower $\mathrm{V}_{\text {th }}$ & Lower $\mathrm{V}_{\mathrm{BD}} ;$ Higher $\mathrm{V}_{\text {th }}$ \\
\hline $\mathrm{S} 2$ & Higher $\mathrm{V}_{\mathrm{BD}} ;$ Higher $\mathrm{V}_{\text {th }}$ & Lower $\mathrm{V}_{\mathrm{BD}} ;$ Lower $\mathrm{V}_{\text {th }} ;$ \\
\hline $\mathrm{S} 3$ & Same $\mathrm{V}_{\mathrm{BD}} ;$ Lower $\mathrm{V}_{\text {th }}$ & Same $\mathrm{V}_{\mathrm{BD}} ;$ Higher $\mathrm{V}_{\text {th }}$ \\
\hline
\end{tabular}


The scenarios discussed here were chosen carefully to investigate the impact of spread in each device parameter during UIS test condition. Moreover, all necessary efforts were made to ensure that the parasitic elements are kept to the minimal as well as balanced for each device since entirely, this investigation focuses on device parameter spread only.

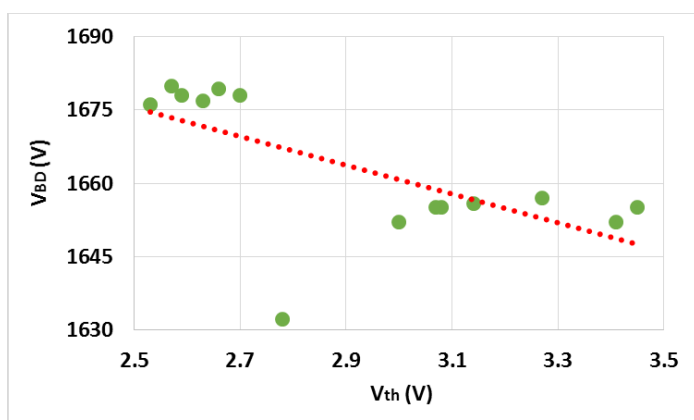

Fig. 5. Measured $\mathrm{V}_{\mathrm{BD}}$ versus $\mathrm{V}_{\text {th }}$ for 14 device samples; $\Delta \mathrm{V}_{\mathrm{BD}}=48 \mathrm{~V}$ for worst case scenario

\subsection{Experimental Results}

Some illustrative waveforms for scenario S1 are presented in Fig. 6 (a) - (c) showing a progressive shift of drain current $\left(I_{D}\right)$ from the device with lower $V_{B D}$ (Dev06) to the device with higher $\mathrm{V}_{\mathrm{BD}}$ (Dev14). The summary of test conditions is presented in Table 2 . The peak avalanche current $\left(\mathrm{I}_{\mathrm{AV}}\right)$ in each device was controlled using input voltage $\left(\mathrm{V}_{\mathrm{DD}}\right)$ and pulse width ( $\left.t_{\text {PULSE }}\right)$ sent to both devices. Here, it is important to note that the current distribution within both devices tend to become a little uniform as $\mathrm{I}_{\mathrm{AV}}$ and avalanche energy $\left(\mathrm{E}_{\mathrm{AV}}\right)$ is increased for both devices. Due to heating up of the devices during avalanche breakdown, $\mathrm{V}_{\mathrm{BD}}$ of the device with lower measured $\mathrm{V}_{\mathrm{BD}}$ value tends to increase which progressively results in voltage level becoming equal to the $\mathrm{V}_{\mathrm{BD}}$ value of the device with higher measured $\mathrm{V}_{\mathrm{BD}}$ value thus explaining the progressive shift in drain currents. In the case of UIS, the energy dissipation during avalanche breakdown stage $\left(\mathrm{E}_{\mathrm{AV}}\right)$ is calculated using equation 2. Moreover, the effect of spread in $\mathrm{R}_{\mathrm{DS}, \mathrm{ON}}$ is also evident by the uneven current sharing during on-state device conduction prior to avalanche breakdown. To demonstrate the mismatch in $\mathrm{V}_{\mathrm{th}}$, a zoom-in of the drain currents for both devices turning off and subsequently entering avalanche phase is also presented in Fig. 7.

$E_{A V}=\frac{1}{2} L_{L O A D} I_{A V}^{2} \cdot \frac{V_{B D}}{V_{B D}-V_{I N}}$

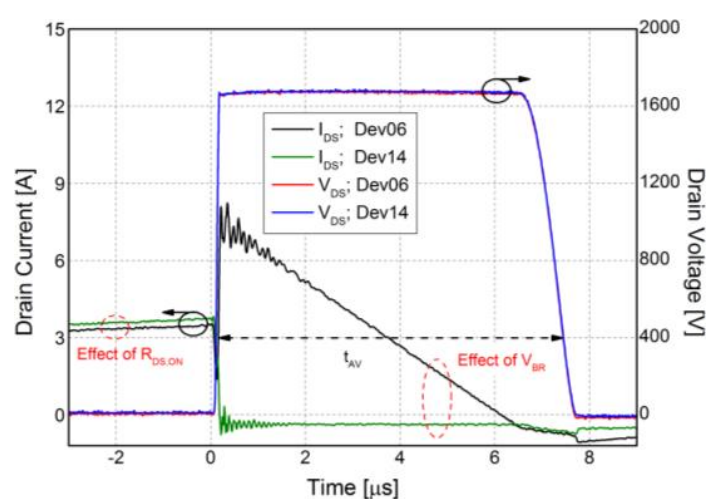

a)

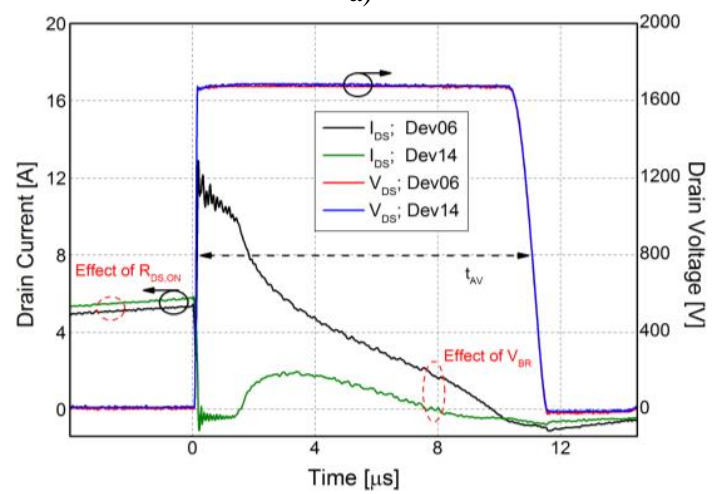

b)

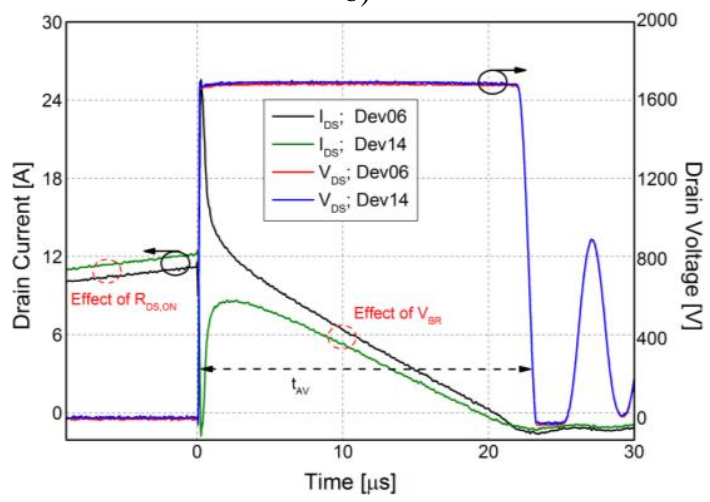

c)

Fig. 6. Progressive shift of drain current during scenario $\mathrm{S} 1, \Delta \mathrm{V}_{\mathrm{BD}}=28 \mathrm{~V}$;

a) $-\mathrm{V}_{\mathrm{DD}}=200 \mathrm{~V}$, tPULSE $\left.=50 \mu \mathrm{s} ; \mathrm{b}\right)-\mathrm{V}_{\mathrm{DD}}=300 \mathrm{~V}$; tPULSE $=50 \mu \mathrm{s} ; \mathrm{c})-\mathrm{V}_{\mathrm{DD}}=400 \mathrm{~V} ;$ tPULSE $=82 \mu \mathrm{s}$

Table 2

Summary of test results presented in Fig. 6; Scenario S1

\begin{tabular}{|l|l|l|}
\hline Scenario & D1 (Dev14) & D2 (Dev06) \\
\hline S1 & $\mathrm{V}_{\mathrm{BD}}=1680 \mathrm{~V} ;$ & $\mathrm{V}_{\mathrm{BD}}=1652 \mathrm{~V} ;$ \\
& $\mathrm{V}_{\mathrm{th}}=2.57 \mathrm{~V} ;$ & $\mathrm{V}_{\mathrm{th}}=3.41 \mathrm{~V} ;$ \\
& $\mathrm{R}_{\mathrm{DS}, \mathrm{ON}}=80 \mathrm{~m} \Omega$ & $\mathrm{R}_{\mathrm{DS}, \mathrm{ON}}=83 \mathrm{~m} \Omega$ \\
\hline \multicolumn{2}{|l}{$\mathrm{T}_{\mathrm{CASE} 1}=\mathrm{T}_{\mathrm{CASE}}=25^{\circ} \mathrm{C} ; \mathrm{L} \mathrm{LOAD}=1 \mathrm{mH} ; \mathrm{V}_{\mathrm{GS}}=18 \mathrm{~V} ;$} \\
$\mathrm{V}_{\mathrm{DD}}=200 \mathrm{~V}-400 \mathrm{~V}$ \\
\hline
\end{tabular}


As can be seen, device having higher $\mathrm{V}_{\text {th }}$ (Dev06) turns-off first followed by the device with lower $\mathrm{V}_{\text {th }}$ (Dev14). Both of the devices start to turn off, however, the device with lower $\mathrm{V}_{\mathrm{BD}}$ immediately goes into avalanche thus the drain current in that device increases taking up all the inductor current. Afterwards, the current sharing between the devices normally depends on how much the device with lower $\mathrm{V}_{\mathrm{BD}}$ heats up creating a progressive shift in drain currents as demonstrated in Fig 6. Another example of scenario S1 is presented in Fig. 8 where a smaller load inductor ( $\mathrm{L}_{\mathrm{LOAD}}$ ) was used to achieve a higher current being switched for the devices. The current being switched was increased to approximately $46 \mathrm{~A}$. For this case, current sharing becomes even more uniform. In Fig. 8, another important observation to be made about the device with higher $\mathrm{V}_{\mathrm{BD}}$ and lower $\mathrm{V}_{\mathrm{th}}$ (Dev11) which doesn't attempt to fully turn-off (current does not go all the way to 0 ) and instead enter avalanche breakdown as a result of an increase of $\mathrm{V}_{\mathrm{BD}}$ for Dev01 as it heated up. Increasing the peak avalanche currents and/or avalanche energies might further facilitate to uniformly distribute currents. However, it is really crucial that the current among devices connected in parallel become perfectly uniform well before the critical energy (i.e. failure) of the device with lower $\mathrm{V}_{\mathrm{BD}}$ (since it is the $1^{\text {st }}$ one to go into avalanche i.e. higher junction temperature $\left(\mathrm{T}_{\mathrm{J}}\right)$ compared to the device with higher $\mathrm{V}_{\mathrm{BD}}$ ). In that case, when the current amongst devices connected in parallel is perfectly uniform, instead of premature failure, one of the device would fail randomly. The test conditions for results presented in Fig. 8 are summarised in Table 3. The results for Dev01 and Dev11 in Fig. 8 show no current unbalance during on-state prior to avalanche breakdown since their $\mathrm{R}_{\mathrm{DS}, \mathrm{ON}}$ values were very close to each other as included in Table 3.

Table 3

Summary of test results presented in Fig. 8; Scenario S1

\begin{tabular}{|l|l|l|}
\hline Scenario & D1 (Dev11) & D2 (Dev01) \\
\hline S1 & $\mathrm{V}_{\mathrm{BD}}=1678 \mathrm{~V} ;$ & $\mathrm{V}_{\mathrm{BD}}=1656 \mathrm{~V} ;$ \\
& $\mathrm{V}_{\mathrm{th}}=2.59 \mathrm{~V} ;$ & $\mathrm{V}_{\mathrm{th}}=3.14 \mathrm{~V} ;$ \\
& $\mathrm{R}_{\mathrm{DS}, \mathrm{ON}}=79 \mathrm{~m} \Omega$ & $\mathrm{R}_{\mathrm{DS}, \mathrm{ON}}=80 \mathrm{~m} \Omega$ \\
\hline \multicolumn{2}{|l}{$\mathrm{T}_{\mathrm{CASE} 1}=\mathrm{T}_{\mathrm{CASE} 2}=25^{\circ} \mathrm{C} ; \mathrm{LLOAD}$} & $=50 \mu \mathrm{H} ; \mathrm{V}_{\mathrm{GS}}=18$ \\
$\mathrm{~V} ; \mathrm{V}_{\mathrm{DD}}=400 \mathrm{~V}$ \\
\hline
\end{tabular}

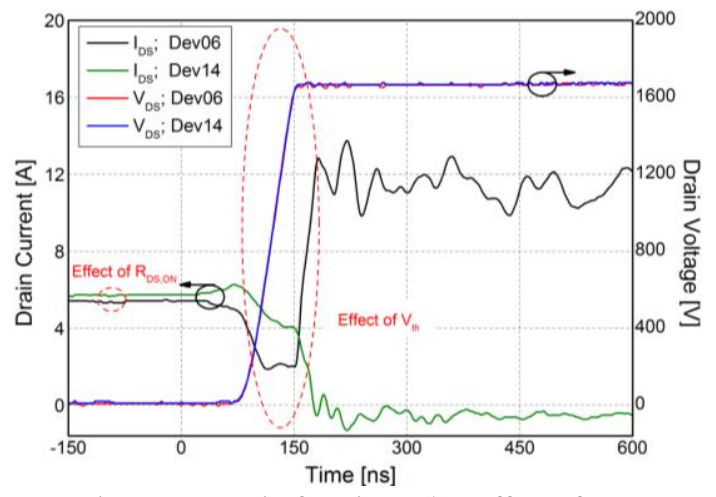

Fig. 7. Zoom-in for Fig. 6 (b); Effect of $V_{\text {th }}$; $\mathrm{V}_{\text {th }}=0.84 \mathrm{~V}$

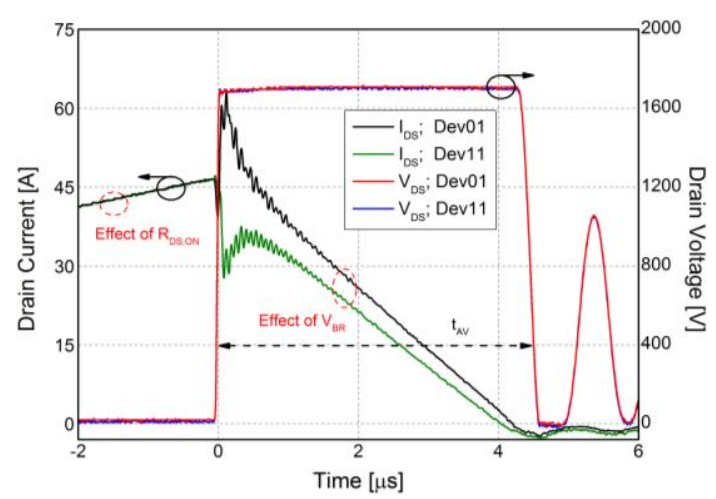

Fig. 8. Scenario S1; Results at higher switching current

Some experimental results representing scenario S2 are also presented in Fig. 9 (a) and (b). Here, the observation regarding the progressive shift in the drain current remains the same as illustrated in Fig. 6. An important point to be noted here is that the current sharing between any two devices for given test conditions would be different depending on how far apart the spread is between the device parameters. However, in this scenario (S2), the device turn-offs are particularly of great interest. Here, since device with lower $\mathrm{V}_{\text {th }}$ also has lower $\mathrm{V}_{\mathrm{BD}}$ (Dev05), it straight away enters avalanche without a decrease in the drain current at turn-off (i.e device does not attempt to turn-off) as shown in Fig 9 (b). Another important point is that even when the device with lower $\mathrm{V}_{\mathrm{BD}}$ heats up to balance the currents, current re-balancing is only partial which does not prevent uneven stresses and potential risk of failure. Moreover, non-uniform current sharing can also result in faster degradation of some devices as compared to others. The test conditions for results presented in Fig. 9 are summarised in Table 4. 

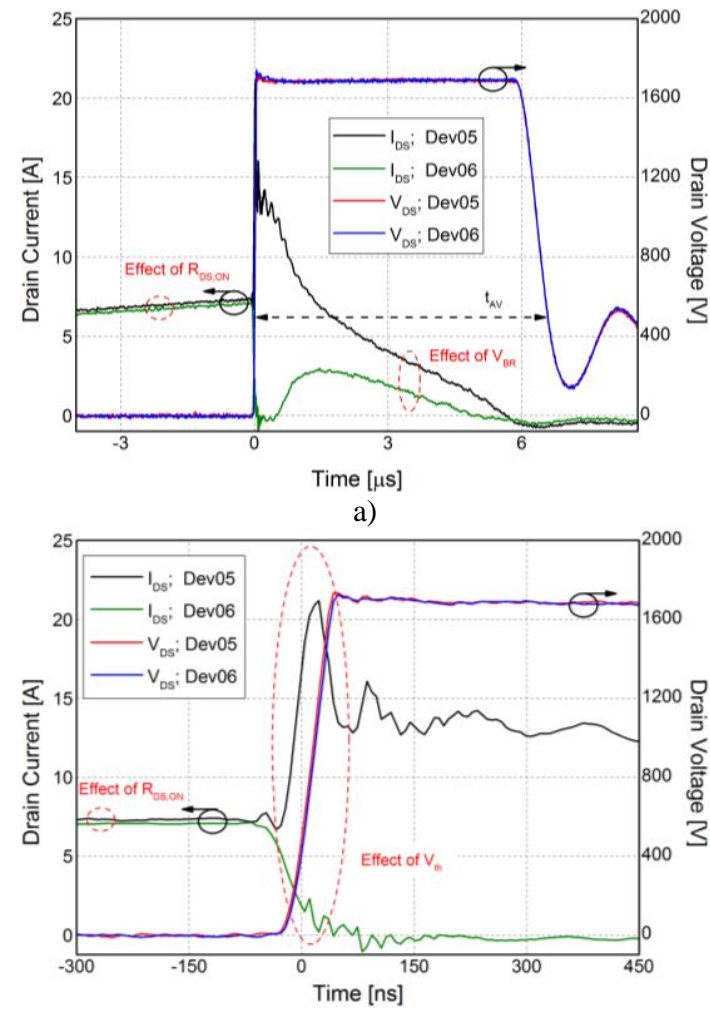

b)

Fig. 9. Scenario S2; a) - Uneven current sharing during avalanche; b) - Zoom-in; Effect of $\mathrm{V}_{\mathrm{th}}$;

Table 4

Summary of test results presented in Fig. 9; Scenario S2

\begin{tabular}{|l|l|l|}
\hline Scenario & D1 (Dev06) & D2 (Dev05) \\
\hline S2 & $\mathrm{V}_{\mathrm{BD}}=1652 \mathrm{~V} ;$ & $\mathrm{V}_{\mathrm{BD}}=1632 \mathrm{~V} ;$ \\
& $\mathrm{V}_{\mathrm{th}}=3.41 \mathrm{~V} ;$ & $\mathrm{V}_{\mathrm{th}}=2.78 \mathrm{~V} ;$ \\
& $\mathrm{R}_{\mathrm{DS}, \mathrm{ON}}=83 \mathrm{~m} \Omega$ & $\mathrm{R}_{\mathrm{DS}, \mathrm{ON}}=84 \mathrm{~m} \Omega$ \\
\hline
\end{tabular}

$\mathrm{T}_{\mathrm{CASE} 1}=\mathrm{T}_{\mathrm{CASE} 2}=25^{\circ} \mathrm{C} ; \mathrm{L}_{\mathrm{LOAD}}=1 \mathrm{mH} ; \mathrm{V}_{\mathrm{GS}}=18 \mathrm{~V}$; $\mathrm{V}_{\mathrm{DD}}=200 \mathrm{~V}$

S3 dictates a scenario when current sharing between both devices would be nearly perfectly uniform. For curiosity, experiments for scenario S3 were also carried out and selected results are presented in Fig. 10. In scenario $\mathrm{S} 3$, effect of spread in $\mathrm{V}_{\text {th }}$ is still present, however, it is prevailed as a result of the devices having approximately the same $\mathrm{V}_{\mathrm{BD}}$ values. Moreover, the spread in $\mathrm{R}_{\mathrm{DS} \text {,ON }}$ is clearly evident from the on-state conduction prior to avalanche state as illustrated in Fig. 10.

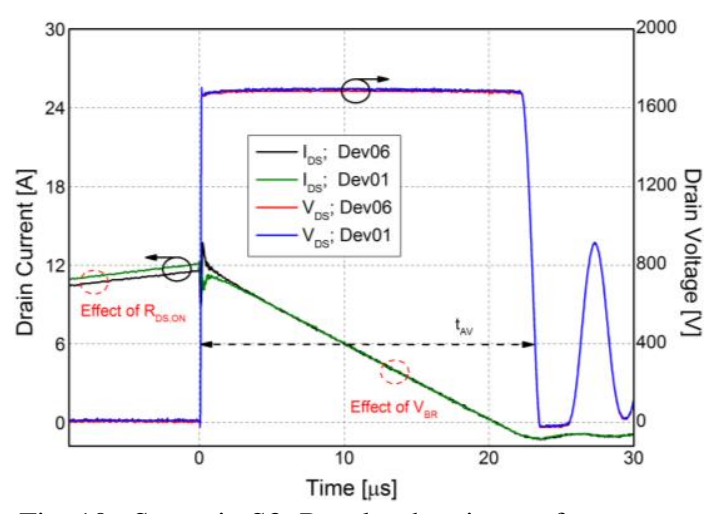

Fig. 10. Scenario S3; Results showing perfect current sharing among devices

Table 5

Summary of test results presented in Fig. 10; Scenario S3

\begin{tabular}{|l|l|l|}
\hline Scenario & D1 (Dev01) & D2 (Dev06) \\
\hline $\mathrm{S} 3$ & $\mathrm{~V}_{\mathrm{BD}}=1656 \mathrm{~V} ;$ & $\mathrm{V}_{\mathrm{BD}}=1652 \mathrm{~V} ;$ \\
& $\mathrm{V}_{\mathrm{th}}=3.14 \mathrm{~V} ;$ & $\mathrm{V}_{\mathrm{th}}=3.41 \mathrm{~V} ;$ \\
& $\mathrm{R}_{\mathrm{DS}, \mathrm{ON}}=79 \mathrm{~m} \Omega$ & $\mathrm{R}_{\mathrm{DS}, \mathrm{ON}}=83 \mathrm{~m} \Omega$ \\
\hline \multicolumn{2}{|l}{$\mathrm{T}_{\mathrm{CASE} 1}=\mathrm{T}_{\mathrm{CASE}}=25^{\circ} \mathrm{C} ; \mathrm{LLOAD}=1 \mathrm{mH} ; \mathrm{V}_{\mathrm{GS}}=18 \mathrm{~V} ;$} \\
$\mathrm{V}_{\mathrm{DD}}=400 \mathrm{~V}$ \\
\hline
\end{tabular}

Ideally, when it comes to paralleling devices, one would want devices without any spread in device electro-thermal parameters. However, this can hardly be the case since device manufacturing procedures would normally introduce some sort of imbalance giving rise to parameter spread. From the results presented here, $\mathrm{SiC}$ power MOSFETs show a wide spread in device parameters even though the values of these parameters are within their ranges provided on the datasheet. It is still needed that the spread in device electro-thermal parameters is contained as an effort at the device manufacturing level (i.e. bare-die device technology). Moreover, to overcome the spread in device parameters, devices should be selected after careful static device characterisation of bare dies prior to packaging of modules having devices connected in parallel. Finally, the failure mechanism of $\mathrm{SiC}$ power MOSFETs can be found in [11]. In [11], investigations have shown that the device fails as a result of thermal runaway. The interpretation of failure mechanism is beyond the scope of this paper. 


\section{Conclusion}

An in-depth understanding of the influence of devices' electro-thermal parameter spread in $\mathrm{SiC}$ power MOSFET technology on the performance of the devices is essential to aid development of robust multichip integrated power modules. Effect of different device parameter spread such as $\mathrm{V}_{\mathrm{th}}, \mathrm{V}_{\mathrm{BD}}$ and $\mathrm{R}_{\mathrm{DS}, \mathrm{ON}}$ have been investigated as part of this study and important observations have been highlighted in this paper. Such investigations are crucial when it comes to paralleling bare-die devices within modules to ensure containment of parameter unbalances to minimize current unbalancing between devices. Moreover, bespoke device package development is also needed to ensure containment of parasitic inductance and thermal impedance unbalances within the module.

\section{References}

[1] Castellazzi, Alberto, Jose Saiz, and Michel Mermet-Guyennet. "Experimental characterisation and modelling of high-voltage IGBT modules off-state thermal instability." In Power Electronics and Applications, 2009. EPE'09. 13th European Conference on, pp. 1-9. IEEE, 2009.

[2] Perpina, Xavier, Alberto Castellazzi, Michel Piton, Guillaume Lourdel, Michel Mermet-Guyennet, and Jose Rebollo. "Temperature Distribution and Short Circuit Events in IGBT-Modules used in Traction Inverters." In Industrial Electronics, 2007. ISIE 2007. IEEE International Symposium on, pp. 799-804. IEEE, 2007.

[3] Li, Jianfeng, Alberto Castellazzi, Mohd Amir Eleffendi, Emre Gurpinar, Christopher Mark Johnson, and Liam Mills. "A Physical RC Network Model for Electrothermal Analysis of a Multichip SiC Power Module." IEEE Transactions on Power Electronics 33, no. 3 (2018): 2494-2508.

[4] Li, Helong, Stig Munk-Nielsen, Xiongfei Wang, Ramkrishan Maheshwari, Szymon Bęczkowski, Christian Uhrenfeldt, and W-Toke Franke. "Influences of device and circuit mismatches on paralleling silicon carbide MOSFETs." IEEE Transactions on Power Electronics 31, no. 1 (2016): 621-634.

[5] Wang, Gangyao, John Mookken, Julius Rice, and Marcelo Schupbach. "Dynamic and static behavior of packaged silicon carbide MOSFETs in paralleled applications." In Applied Power Electronics Conference and Exposition (APEC), 2014 Twenty-
Ninth Annual IEEE, pp. 1478-1483. IEEE, 2014.

[6] Sadik, Diane-Perle, Juan Colmenares, Dimosthenis Peftitsis, Jang-Kwon Lim, Jacek Rabkowski, and HansPeter Nee. "Experimental investigations of static and transient current sharing of parallel-connected silicon carbide MOSFETs." In Power Electronics and Applications (EPE), 2013 15th European Conference on, pp. 1-10. IEEE, 2013.

[7] Chinthavali, Madhu, Puqi Ning, Yutian Cui, and Leon M. Tolbert. "Investigation on the parallel operation of discrete SiC BJTs and JFETs." In Applied Power Electronics Conference and Exposition (APEC), 2011 Twenty-Sixth Annual IEEE, pp. 1076-1083. IEEE, 2011.

[8] Wang, Zhiqiang, Xiaojie Shi, Leon M. Tolbert, Fred Wang, Zhenxian Liang, Daniel Costinett, and Benjamin J. Blalock. "Temperature-dependent shortcircuit capability of silicon carbide power MOSFETs." IEEE Transactions on Power Electronics 31, no. 2 (2016): 1555-1566.

[9] Castellazzi, Alberto, Asad Fayyaz, Gianpaolo Romano, Michele Riccio, Andrea Irace, Jesus UrrestiIbanez, and Nick Wright. "Transient out-of-SOA robustness of SiC power MOSFETs." In Reliability Physics Symposium (IRPS), 2017 IEEE International, pp. 2A-3. IEEE, 2017.

[9] Kelley, Mitchell D., Bejoy N. Pushpakaran, and Stephen B. Bayne. "Single-Pulse Avalanche Mode Robustness of Commercial $1200 \mathrm{~V} / 80 \mathrm{~m} \Omega \mathrm{SiC}$ MOSFETs." IEEE Transactions on Power Electronics 32, no. 8 (2017): 6405-6415.

[11] Fayyaz, Asad, Alberto Castellazzi, Gianpaolo Romano, Michele Riccio, Andrea Irace, Jesus Urresti, and Nick Wright. "UIS failure mechanism of SiC power MOSFETs." In Wide Bandgap Power Devices and Applications (WiPDA), 2016 IEEE 4th Workshop on, pp. 118-122. IEEE, 2016. 